Check for updates

Montreal

Cite this as: $B M / 2022 ; 376: 0112$ http://dx.doi.org/10.1136/bmj.0112 Published: 14 January 2022

\title{
Covid-19: Quebec to tax the unvaccinated as vaccine mandates spread in Europe
}

Owen Dyer

Quebec's plan to charge adults not vaccinated against coronavirus a "health contribution" fee will go ahead, the province's premier François Legault said on 13 January, despite getting a cool reception from the Canadian federal government and the leaders of other provinces, several of whom said they would not be copying the idea.

The amount to be charged has not been revealed, but will be "significant," Legault said, promising that a bill will be presented to the legislature early in February.

"Those who refuse to get the shot bring a financial burden to hospital staff and Quebecers," said the premier. "This $10 \%$ of the population can't burden the $90 \%$."

With $89 \%$ of its residents aged over 12 fully vaccinated, Quebec does not lag other provinces in coverage, but has persistently outpaced the rest of Canada in cases and deaths. This week Horacio Arruda, who has been the provincial government's scientific adviser since the beginning of the pandemic, resigned after much criticism from independent experts.

As in the UK, Quebec's government briefly suggested a herd immunity strategy in 2020, then dropped it after an outcry from scientists. A high early burden of deaths in elderly care was blamed on the government's practice of rotating workers between different care homes. More recent criticism has focused on the shortage of rapid tests and the delay in providing booster shots.

\section{Public support}

Polling suggests that Quebec's population is more open to vaccine mandates than the rest of Canada. Last week the province made proof of vaccination a requirement for entry into its cannabis shops and state monopoly liquor stores. This prompted a surge in first dose vaccination bookings from 1500 a day to 60oo, said Quebec's health minister Christian Dubé. That number dipped after a few days but has surged back to 7000 in the wake of the "health contribution" announcement, Dubé later said.

Some legal experts doubt if the proposed tax will withstand constitutional legal challenge. The Canada Health Act promises equal access to free healthcare for all.

"Allowing the government to levy fines on those who do not agree with the government's recommended medical treatment is a deeply troubling proposition," said Cara Zwibel, the acting general counsel for the Canadian Civil Liberties Association.
Several critics suggested that the tax could lead to a slippery slope in which smokers and overweight people are charged more for their healthcare. In fact, Canada has for years taken in more money from cigarette taxes than it spends on treating smoking related diseases. Research suggests that smokers and the obese consume fewer health resources over their lifetimes than healthier people, because they die younger. $^{12}$

Quebec remains an outlier in North America, where libertarian attitudes prevail. The Biden administration's efforts to enforce vaccination have mostly been struck down or put on hold by Republican appointed judges. On 13 January, the US Supreme Court struck down a vaccine mandate for companies with more than 100 employees, although it allowed the federal government's health worker vaccine mandate to stand.

Other countries with coronavirus vaccine mandates include Turkmenistan-despite its government's denial of any covid cases in the country-and Indonesia, which imposed a mandate over a year ago but has not procured the vaccine supplies needed to effectively implement it. Indonesia is currently requiring citizens to pay for a third dose out of their own pocket.

Costa Rica and Ecuador announced vaccine mandates in November and December that include children aged over five.

\section{Government attitudes harden in Europe}

It is in Europe, however, that the move towards compulsory measures has been most pronounced. On 17 January, Greece will begin imposing monthly fines on over 6 os who remain unvaccinated. The fine will be $€_{50}$ this month, rising to $€_{100}$ a month from February. Austria has already begun fining the unvaccinated and ordering lockdowns that apply only to them.

Earlier this month, Italy announced a vaccine mandate for the over 50 backed by a sliding scale of fines that starts at $€ 100$ but could rise to as much as $€ 1600$ for an unvaccinated worker over 50 who attends work in February. A raft of other restrictions includes denial of public transport to the unvaccinated-causing an outcry in Venice where many citizens will be stranded on small islands as a result.

France will extend its vaccine passport scheme in a bid to "piss off the unvaccinated," according to President Emmanuel Macron. But polling by Ipsos in France and Italy found the unvaccinated less hostile to mandates than might be expected, with $23 \%$ of 
unvaccinated French respondents supporting a mandate and 16\% expressing no opinion. ${ }^{3}$

This result appears to bolster an argument made by two Harvard Medical School professors last month in the New York Times. ${ }^{4}$ Anupam Jena and Christopher Worsham wrote that vaccine mandates meet less resistance than a campaign of persuasion, because people are used to being simply required to do things they dislike, such as paying taxes, whereas voluntary campaigns demand that they revise strongly held views and admit that their previous position was wrong, a far harder proposition.

1 van Baal PHM, Polder JJ, de Wit GA, etal. Lifetime medical costs of obesity: prevention no cure for increasing health expenditure. PLoS Med 2008;5:e29.

doi: 10.1371/journal.pmed.0050029 pmid: 18254654

2 Tovey M. Obesity and the public purse: weighing up the true cost to the taxpayer. Institute of Economic Affairs. January 2017. https://iea.org.uk/wp-content/uploads/2017/01/Obesity-and-thePublic-Purse-PDF.pdf.

3 Walt $\mathrm{V}$, Warner B. Even the unvaccinated in Italy and France are surprisingly okay with new hard-line vaccine mandates. Fortune. 7 January 2022. https://fortune.com/2022/01/07/unvaccinated-italy-france-ipsos-poll-covid-vaccine-mandate.

4 Jena AB, Worsham CM. Facts alone aren't going to win over the unvaccinated. this might. New York Times. 21 December 2021. www.nytimes.com/2021/12/21/opinion/vaccine-hesitancy-covidomicron.html.

This article is made freely available for personal use in accordance with BMJ's website terms and conditions for the duration of the covid-19 pandemic or until otherwise determined by BMJ. You may download and print the article for any lawful, non-commercial purpose (including text and data mining) provided that all copyright notices and trade marks are retained. 